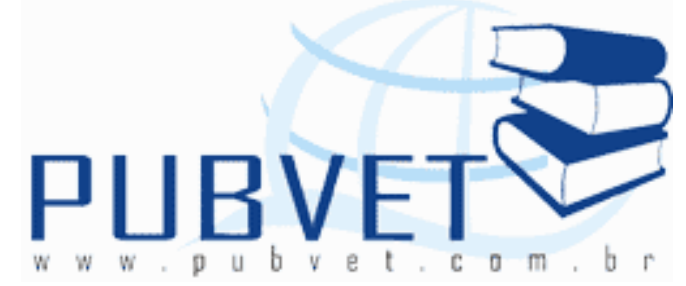

PUBVET, Publicações em Medicina Veterinária e Zootecnia.

\title{
Avaliação da carcaça de caprinos e ovinos
}

José Carlos da Silveira Osório ${ }^{1,2,3}$; Maria Teresa Moreira Osório ${ }^{2,3}$; Otoniel Geter Lauz Ferreira ${ }^{3}$; Fernando Miranda de Vargas Junior ${ }^{4}$; Alexandre Rodrigo Mendes Fernandes ${ }^{4}$; Hélio de Almeida Ricardo5; Luis Gustavo Castro Alves ${ }^{4}$; Marco Antonio Previdelli Orrico Júnior ${ }^{5}$

${ }^{1}$ Professor Visitante Nacional Sênior da UFGD/CAPES. ${ }^{2}$ Bolsista do CNPq. ${ }^{3}$ Universidade Federal de Pelotas. ${ }^{4}$ Universidade Federal da Grande Dourados. ${ }^{5}$ UFGD - PNPD-Institucional da CAPES.

\section{Resumo}

No mercado da carne e na prática de comercialização, o valor das carcaças é estabelecido em função da adequação de suas características quantitativas e qualitativas as exigências da demanda. Nesse sentido, o trabalho apresenta como avaliar a carcaça de caprinos e ovinos, descrevendo técnicas e colocando de manifesto nossa opinião científica e prática, da importância, de acordo com a finalidade com que se avalia a carcaça. Conclui-se que o aperfeiçoamento dos processos de produção e de comercialização para obtenção de produto de qualidade será consolidado se existirem técnicas claras e práticas para descrever os caracteres relacionados com a qualidade da carne, que possam ser medidos na carcaça e que tenham relação biológica com a avaliação no animal. 
OSÓRIO, J.C.S. et al. Avaliação da carcaça de caprinos e ovinos. PUBVET, Londrina, V. 6, N. 23, Ed. 209, Art. 1403, 2012.

\section{Evaluation of the carcass of goat and sheep}

\section{Summary}

In the market of the meat and the practical one of commercialization, the value of the carcasses is established in function of the adequacy of its quantitative and qualitative characteristics the requirements of the demand. In this direction, the work presents as to evaluate the carcass of goat and sheep, describing techniques of the characteristics and placing of manifest our scientific and practical opinion, of the importance, in accordance with the purpose with that if it evaluates the carcass. One concludes that the perfectioning of the commercialization and production processes, for attainment of quality product, will be consolidated to exist techniques clear and practical to describe the characters related with the quality of the meat, that can be measured in the carcass and that they have a biological relation with an alive evaluation in the animal.

\section{INTRODUÇÃO}

A carcaça é o produto da cadeia da carne de suma importância nas transações comerciais e sua descrição o mais detalhada possível sempre foi e continua sendo, motivo de estudos para evitar equívocos não somente na comercialização, mas, também, na busca de mútuo entendimento entre o produtor e o consumidor; assim como na comparação de resultados de pesquisas. Entretanto, não basta a descrição detalhada da carcaça, mas, além disso, conhecer as relações biológicas das características da carcaça com as do animal e da carne; somente assim, pode-se organizar a cadeia produtiva.

Colocamos de manifesto que, o aperfeiçoamento dos processos de produção e de comercialização na obtenção de produto de qualidade, será consolidado se existir técnicas claras e práticas para descrever os caracteres relacionados com a qualidade da carne, que possam ser medidos na carcaça e que tenham relação biológica com a avaliação "in vivo". 
OSÓRIO, J.C.S. et al. Avaliação da carcaça de caprinos e ovinos. PUBVET, Londrina, V. 6, N. 23, Ed. 209, Art. 1403, 2012.

A utilização das características descritivas da carcaça depende da finalidade com que esta é realizada e, a eleição adequada tem sido motivo de simpósios, cursos, etc.; o aspecto econômico, a facilidade e a precisão tem sido a constante dos debates.

Procurou-se evitar a repetição de citações bibliográficas; mas, a base, com modificações e/ou adaptações neste documento estão nas publicações de Sierra (1974), Colomer (1979, 1986), Müller (1987), Colomer et al. (1988), Osório et al. (1998), Cañeque e Sañudo (2000, 2005), Osório et al. (2002) e Osório e Osório (2003).

Não serão descritas as características avaliadas no animal (in vivo) e na carne, mas serão citadas, a seguir, e relacionadas com as implicações biológicas na carcaça.

Características avaliadas no animal: genótipo, idade (na falta de controle e identificação da natalidade, pode ser avaliada através da dentição), sendo que de acordo com a idade e sexo é feita uma separação em categoria (cordeiro macho e fêmea, borrego, capão, ovelha, etc.), peso corporal ao nascer e em diferentes idades (normalmente, de 28 em 28 dias), peso corporal ao abate (com e sem jejum, peso corporal vazio), condição corporal (por palpação), conformação (visual), comprimento corporal, altura do posterior e do anterior, perímetro torácico, ultrassom em tempo real, tomografia axial computadorizada, ressonância magnética nuclear e análises pela ativação de neutrons. A partir dessas características são calculados os ganhos de peso corporal diário, nos intervalos das tomadas de peso e a compacidade corporal.

Em rebanho comercial, na prática, em nível de campo, o animal destinado ao abate (sadio) é avaliado pelo peso, condição corporal e a morfologia. O peso corporal apresenta alta relação com o peso da carcaça e com os cortes e composição dos tecidos desta e a condição corporal está relacionada com a terminação e estado de engorduramento da carcaça.

Características avaliadas na carne: $\mathrm{pH}$ e sua queda, cor, textura (a textura é uma propriedade sensorial e a dureza é um atributo de textura), capacidade de retenção de água (perdas por oreio, cozimento ou por pressão), 
OSÓRIO, J.C.S. et al. Avaliação da carcaça de caprinos e ovinos. PUBVET, Londrina, V. 6, N. 23, Ed. 209, Art. 1403, 2012.

composição química (água, proteína, gordura, minerais, cinzas), sendo que entre as proteínas é importante analisar a quantidade e solubilidade do colágeno, pois este influirá sobre a dureza final da carne cozida, tal como é percebida pelo consumidor. Determinação sensorial da qualidade da carne (aparência, cheiro, flavor e textura oral, são os atributos sensoriais habitualmente utilizados). Sendo que, na textura oral são determinadas a dureza, suculência, mastigabilidade, untuosidade, resíduo, maciez, fibrosidade, elasticidade, gomosidade, adesão, pastosidade, etc. Composição dos ácidos graxos da gordura. Análises dos compostos voláteis. Análises de fibras musculares (através de métodos bioquímicos, histoquímicos e inmunohistoquímicos).

Na prática, o consumidor é que determina as características de maior importância na carne através do grau de satisfação que o produto the proporciona e, esse grau de satisfação não é estático (varia no espaço e no tempo) e não são poucos os fatores extrínsecos e intrínsecos ao consumidor e a carne que interferem sobre o grau de satisfação. A gordura propicia o sabor a porção comestível e, indiretamente, a suculência, principalmente. Outra característica de máxima importância é a maciez da carne, que está relacionada a idade; por isso, a carne de cordeiro (animal jovem) é mais apreciada pelo consumidor.

Quanto à carcaça, as características utilizadas para sua avaliação são: peso, $\mathrm{pH}$, perdas ao resfriamento, conformação, estado de engorduramento, comprimento interno (medida $\mathrm{L}$ ) e externo (medida $\mathrm{K}$ ), comprimento da perna (medida F), profundidade do peito (medida $\mathrm{TH}$ ), largura do peito (medida $\mathrm{Wr}$ ), largura da garupa (medida $G$ ), perímetro da garupa (medida B), largura e profundidade da perna, comprimento do osso metacarpiano, área do músculo longissimus dorsi (área de olho de lombo), medidas A (largura) e B (profundidade) do músculo longissimus dorsi, espessura da gordura de cobertura (medida C), espessura da gordura sobre a costela (medida $\mathrm{J}$ ), textura, marmoreio e cor do músculo longissimus dorsi, cor da gordura, consistência da gordura, quantidade de gordura perirrenal e pélvica, 
OSÓRIO, J.C.S. et al. Avaliação da carcaça de caprinos e ovinos. PUBVET, Londrina, V. 6, N. 23, Ed. 209, Art. 1403, 2012.

composição regional ou anatômica (cortes), composição tecidual (kg e \% de osso, músculo e gordura e relação entre esses, principalmente, mas, existem outros componentes, caso dos tendões, vasos ...), compacidade da carcaça e da perna, medida GR e musculosidade da carcaça.

A utilização dessas características depende dos objetivos; na pesquisa todas podem ser avaliadas.

\section{CARACTERÍSTICAS DA CARCAÇA}

Para estabelecer o preço da carcaça, existem critérios de eleição, constantes no espaço e no tempo, pelos quais se rege a oferta e a demanda e cuja importância relativa é o principal fator na determinação do preço. Os caracteres de composição da carcaça e o rendimento dos três tecidos fundamentais que a integram, osso, músculo e gordura são os determinantes do valor da carcaça. Estes caracteres são conseqüência de processos biológicos determinados pela raça e sexo e podem variar com o peso e idade de abate e, modificados por fatores ambientais, principalmente pela alimentação.

Como conseqüência dos diferentes sistemas de produção e das raças neles implicadas, o mercado internacional da carne apresenta grande heterogeneidade nos caracteres quantitativos e qualitativos que definem os distintos tipos de carcaças comercializadas. Esta variabilidade, longe de ser inconveniente para a comercialização, representa considerável vantagem, por permitir oferecer ao mercado carcaças diferentes, que podem satisfazer as variadas preferências da demanda.

Nos distintos países do mundo, implicados no comércio internacional da carne, prevalecem nos sistemas de avaliação, como critérios básicos, quatro caracteres: peso da carcaça, idade cronológica, estado de engorduramento e conformação. Sendo que o sistema de produção, especialmente a alimentação, é determinante sobre as carcaças dos caracteres quantitativos: peso da carcaça e idade cronológica. Por outro lado, a raça é responsável pela variação dos caracteres que condicionam a qualidade: engorduramento e conformação. Portanto, a raça e o sistema de produção são importantes na uniformidade. 
OSÓRIO, J.C.S. et al. Avaliação da carcaça de caprinos e ovinos. PUBVET, Londrina, V. 6, N. 23, Ed. 209, Art. 1403, 2012.

\section{PESO DA CARCAÇA E PERDAS POR RESFRIAMENTO}

O peso da carcaça é uma característica de fácil medida objetiva e que oferece mínimos riscos de erro em sua determinação. Existe alta relação entre o peso da carcaça e os três principais tecidos que a compõem: osso, músculo e gordura. Quando o peso da carcaça aumenta, o peso de osso, músculo e gordura aumentam em valor absoluto; mas, em valor relativo não acontece o mesmo. Quando o peso da carcaça aumenta, normalmente, a proporção de osso diminui, a de músculo permanece constante e a de gordura aumenta. Porém, há variação no crescimento e desenvolvimento dos tecidos da carcaça, em relação ao peso desta depende da espécie e dentro de espécie, cada raça ou genótipo, apresenta um modelo de desenvolvimento ou velocidade de formação dos componentes do corpo e da carcaça. Esta velocidade de desenvolvimento varia, com a alimentação; embora existam outros fatores, como é o caso do formato. As raças de grande formato ou peso adulto elevado depositam seus tecidos corporais a velocidades relativas mais lentas (tardias) que as raças de pequeno formato ou de peso adulto pouco elevado (precoces). Portanto, carcaças de igual peso podem apresentar composição corporal e tecidual diferente. Quando se toma como critério de desenvolvimento a idade cronológica do animal se observa que a igual idade os animais de diferente formato apresentam distintos pesos e composição corporal.

Portanto, a similar peso corporal ou idade a proporção de osso, músculo e gordura depende do formato, ou seja, depende se a raça é precoce ou tardia.

Isso indica que para cada raça existe uma idade ou peso ótimo de abate para o qual a relação músculo:gordura seja aquela preferida pelo consumidor e a de osso seja adequada para sustentação e funcionalidade do animal.

Há dois tipos de peso tomados na carcaça: o de carcaça quente e o de carcaça fria. O primeiro tomado logo após o abate e o outro, após determinado período em câmara fria. Porém, o peso da carcaça indica pouco quando não se define a carcaça. Por exemplo, com os rins e gordura renal e pélvica, com ou sem cabeça e cola. Nos experimentos dos autores a cabeça é retirada, assim como as patas, permanecendo a cola e a gordura renal e pélvica. 
OSÓRIO, J.C.S. et al. Avaliação da carcaça de caprinos e ovinos. PUBVET, Londrina, V. 6, N. 23, Ed. 209, Art. 1403, 2012.

Após o abate, a prática de cortar o tendão depois do pescoço, permite melhor acondicionamento da carcaça na câmara de resfriamento.

As condições de resfriamento devem ser especificadas: tempo, temperatura, se em câmara com ar forçado ou não, principalmente, já que, esses fatores, vão influir sobre as perdas que sofrem a carcaça, ou seja, as perdas por resfriamento, que é a diferença entre o peso de carcaça quente (PCQ) e de carcaça fria (PCF). Diferença essa, normalmente expressa em kg e percentagem: \% Perdas ao resfriamento $=[(P C Q-P C F) \times 100] \div P C Q$.

Em nossos experimentos, as carcaças são colocadas em câmara fria com ar forçado durante 24 horas, à temperatura de $1^{\circ} \mathrm{C}$; a seguir, são retiradas, pesadas e avaliadas.

\section{CONFORMAÇÃO}

Com certeza, no passado, o progresso em produção animal foi obtido quase que exclusivamente com o aperfeiçoamento da morfologia (através de sua avaliação visual, ou seja, de sua conformação). Concretizando essa importância, em 1974 a Associação Européia de Produção Animal (De Boer et al., 1974) definiu a conformação como sendo a espessura da carne e da gordura subcutânea, com relação às dimensões do esqueleto.

Sendo a carcaça um corpo composto e admitindo-se que seus três principais componentes são o osso, músculo e a gordura, conforme referido na definição da Associação Européia de Produção Animal, a forma deste conjunto depende:

1. da massa absoluta ou relativa de cada um dos componentes do conjunto;

2. da forma de cada um dos componentes para uma mesma massa e

3. da posição que ocupa no conjunto cada um deles.

Os três fatores mencionados modificam a impressão visual que causa no observador o conjunto de osso, músculo e gordura, que integram a carcaça, e o resultado das medidas objetivas que sobre ela se realizam.

A conformação pode ser estimada visualmente, de forma subjetiva, ou através de medidas da carcaça ou relação entre essas medidas. A 
OSÓRIO, J.C.S. et al. Avaliação da carcaça de caprinos e ovinos. PUBVET, Londrina, V. 6, N. 23, Ed. 209, Art. 1403, 2012.

denominação conformação, normalmente, é adotada em nossos experimentos e publicações, para avaliação subjetiva e quando referimo-nos as medidas objetivas, denominamos de morfologia da carcaça.

A legislação comunitária (CEE) regulamenta a avaliação da conformação por apreciação visual da forma das carcaças com mais de $13 \mathrm{~kg}$. Para carcaças com menos de $13 \mathrm{~kg}$, a legislação comunitária não leva em consideração a avaliação da conformação. Entretanto, do ponto de vista experimental é recomendada sua utilização, mediante escala e padrões fotográficos, como os elaborados por Colomer et al. (1988).

A conformação visual pode ser tomada na carcaça quente ou fria e por ser uma avaliação subjetiva, o melhor é fazer uma ordenação comparativa e/ou utilizar padrões fotográficos.

Em nossos experimentos utilizamos os padrões fotográficos, com a carcaça suspensa pelos membros posteriores, com ganchos de dimensões padrões, sem que as extremidades posteriores sejam cruzadas, ou seja, mantendo-se entre as articulações tarso-metatarsianas separadas por uma distância pré-fixada, de maneira que as tíbias fiquem paralelas. Normalmente, $12 \mathrm{~cm}$ para carcaças entre 11 e $14 \mathrm{~kg} ; 10 \mathrm{~cm}$ para carcaças entre 8 e $11 \mathrm{~kg} \mathrm{e}$, essa separação pode ser de $6,5 \mathrm{~cm}$ para carcaças mais leves e de $14 \mathrm{~cm}$ para carcaças mais pesadas; ou seja, observar que as tíbias fiquem paralelas.

Na conformação visual da carcaça é feita uma avaliação da forma como um todo e tendo em consideração, nas distintas regiões anatômicas, a espessura de seus planos musculares e adiposos em relação ao tamanho do esqueleto que os suportam.

A conformação é utilizada para descrever a forma da carcaça e traduzir a impressão visual que causa no observador.

Considera-se que carcaça bem conformada é a que apresenta em cada região anatômica dominância dos perfis convexos e dos diâmetros transversais frente aos perfis côncavos e dos diâmetros longitudinais, ou seja, com forma curta, larga, redonda e compacta e, ao contrário, as carcaças longas e estreitas são consideradas de conformação deficiente. 
OSÓRIO, J.C.S. et al. Avaliação da carcaça de caprinos e ovinos. PUBVET, Londrina, V. 6, N. 23, Ed. 209, Art. 1403, 2012.

Portanto, há relação entre o desenvolvimento, forma dos músculos e composição física da carcaça com a conformação.

Em ovinos, a raça e a importância da gordura de cobertura ou subcutânea são os fatores que mais influem na forma da carcaça. Porém, em caprinos, a escassa e fina capa de gordura de cobertura sugere que a conformação seja um indicador mais valioso do conteúdo de carne da carcaça do que em ovinos e bovinos.

A especificação objetiva da conformação, compacidade da carcaça, através do quociente peso da carcaça/comprimento da carcaça é uma maneira comparativa de grande validade para carcaças ovinas e caprinas.

$\mathrm{Na}$ prática é recomendado que seja avaliada a conformação por duas pessoas com experiência e que uma delas tenha conhecimentos técnicos.

Os índices utilizados na avaliação da conformação da carcaça são os mesmos para avaliar a conformação do animal (Tabela 1) e a escala ou índices de conformação da carcaça, são semelhantes aos descritos por Colomer et al. (1988), que segue a metodologia de Dumont (1971).

Outras informações sobre morfologia in vivo, conformação do animal e da carcaça podem ser verificadas em Osório et al. (2002).

Tabela 1. Conformação da carcaça.

\begin{tabular}{|l|l|}
\hline ÍNDICE & NOMENCLATURA \\
\hline 1,0 & MUITO POBRE \\
\hline 1,5 & POBRE \\
\hline 2,0 & ACEITÁVEL \\
\hline 2,5 & MÉDIA \\
\hline 3,0 & BOA \\
\hline 3,5 & MUITO BOA \\
\hline 4,0 & SUPERIOR \\
\hline 4,5 & MUITO SUPERIOR \\
\hline 5,0 & EXCELENTE \\
\hline
\end{tabular}


OSÓRIO, J.C.S. et al. Avaliação da carcaça de caprinos e ovinos. PUBVET, Londrina, V. 6, N. 23, Ed. 209, Art. 1403, 2012.

\section{ESTADO DE ENGORDURAMENTO}

O estado de engorduramento da carcaça é feito por apreciação visual, avaliando-se a gordura de cobertura em quantidade e distribuição. Também se entende por estado de engorduramento a proporção de gordura que apresentam as carcaças em relação ao seu peso.

Um indicativo prático utilizado é o de quanto coberto ou descoberto estão os rins, "janela de gordura dos rins"; ao considerar a gordura renal e pélvica deve-se ter cuidado, visto que, as raças mais rústicas, como é o caso da Crioula, no Rio Grande do Sul, há maior deposição de gordura interna; aspecto semelhante ocorre com a raça Pantaneira. Portanto, a janela de gordura dos rins pode levar a erro na avaliação do estado de engorduramento da carcaça. Assim, uma carcaça pode apresentar pouca gordura de cobertura e muita gordura renal e pélvica. Logo, a utilização da gordura renal e pélvica, na avaliação do estado de engorduramento, requer familiaridade com a raça.

Colomer et al. (1988) classificam as carcaças, de acordo com a gordura que cobrem os rins e a cavidade pélvica, por apreciação visual, em:

Índice 1. Pouca. Os rins somente estão cobertos de gordura em seu extremo caudal. A cavidade pélvica está coberta por uma fina capa de gordura.

Índice 2. Normal. Os rins estão parcialmente cobertos de gordura. A gordura na cavidade pélvica é aparente, mas de média espessura.

Índice 3. Muita. Os rins estão totalmente cobertos de gordura e a capa que os cobre é muito grossa. A cavidade pélvica apresenta acúmulos de gordura aparentes.

Nos experimentos dos autores, a avaliação do estado de engorduramento, é feita, na carcaça fria, suspendida da mesma forma que para conformação. $O$ estado de engorduramento é realizado, preferencialmente, de maneira comparativa e com ordenação sequencial das carcaças e avaliação da gordura de cobertura e interna, utilizando-se padrões fotográficos e a descrição dos índices de acordo com Colomer et al. (1988). 
OSÓRIO, J.C.S. et al. Avaliação da carcaça de caprinos e ovinos. PUBVET, Londrina, V. 6, N. 23, Ed. 209, Art. 1403, 2012.

$\mathrm{Na}$ avaliação do estado de engorduramento da carcaça atribui-se índice de 1 a 5 (Tabela 2). A separação de 0,5 é para diferenças pequenas de engorduramento e servem mais na prática e não para descrição teórica.

Tabela 2. Estado de engorduramento da carcaça.

\begin{tabular}{|l|l|}
\hline ÍNDICE & NOMENCLATURA \\
\hline 1,0 & EXCESSIVAMENTE MAGRA \\
\hline 1,5 & MUITO MAGRA \\
\hline 2,0 & MAGRA \\
\hline 2,5 & LIGEIRAMENTE MAGRA \\
\hline 3,0 & NORMAL \\
\hline 3,5 & LIGEIRAMENTE ENGORDURADA \\
\hline 4,0 & GORDA \\
\hline 4,5 & MUITO GORDA \\
\hline 5,0 & EXCESSIVAMENTE GORDA \\
\hline
\end{tabular}

Índice 1. Sem gordura de cobertura. Carcaça excessivamente magra. A gordura de cobertura é muito escassa e praticamente ausente na superfície. Índice 2. Com gordura de cobertura escassa. Carcaça magra. Ausência relativa da gordura de cobertura. Os grupos musculares são superficialmente visíveis nas pernas e paletas; porém, as regiões lombar e dorsal estão cobertas por fina capa de gordura através da qual os músculos subjacentes são visíveis.

Índice 3. Normal. Gordura de cobertura medianamente desenvolvida. A totalidade da musculatura, a exceção das costelas e pernas, está coberta por uma capa de gordura de mediana espessura que não deixa revelarem-se os músculos subjacentes. Acúmulos de gordura são aparentes nas regiões da nuca, cruzes e na volta do implante da cola.

Índice 4. Carcaça gorda. Gordura de cobertura desenvolvida. Toda a musculatura superficial da carcaça está coberta com espessa capa de gordura; porém, alguns grupos musculares são parcialmente visíveis nas partes distais 
OSÓRIO, J.C.S. et al. Avaliação da carcaça de caprinos e ovinos. PUBVET, Londrina, V. 6, N. 23, Ed. 209, Art. 1403, 2012.

das pernas e paletas. Acúmulos de gordura em forma de estrias aparecem nas regiões dorsal e lombar.

Índice 5. Excessivamente gorda. Gordura de cobertura muito desenvolvida. A carcaça está coberta por um manto de gordura em sua totalidade. Espessos depósitos de gordura em forma de estrias proeminentes aparecem nas regiões dorsal e lombar. As pernas e as paletas, principalmente esta última que é mais precoce, estão quase completamente cobertas por uma capa espessa de gordura e a gordura situada entre os grupos musculares são proeminentes e obscurecem a delimitação entre eles.

O estado de engorduramento da carcaça é o elo para o entendimento entre 0 que $o$ consumidor deseja de gordura e 0 que $o$ produtor pode conseguir, através da condição corporal do animal.

A relação entre o estado de engorduramento e a condição corporal animal é importante, assim como as equações de regressão entre essas duas variáveis, para quantificar e melhorar a acuracidade dos avaliadores. Felizmente, existe alta relação entre a condição corporal e o estado de engorduramento da carcaça (Osório et al., 2005, 2006 e Esteves et al., 2010).

Depois de avaliada a conformação e o estado de engorduramento da carcaça, separa-se a carcaça em duas metades longitudinais simétricas, com o auxílio de serra elétrica, de preferência, podendo ser feito com serra mecânica, deixando a cola na metade direita.

A metade direita da carcaça é destinada para separação regional em cortes e na metade esquerda são realizadas as demais medidas e avaliações (que serão descritas a seguir).

\section{COMPRIMENTO DA CARCAÇA}

$\mathrm{Na}$ carcaça pode ser tomado o comprimento externo ou medida $\mathrm{K}$ e o comprimento interno ou medida L. Normalmente, os autores tomam o comprimento interno da carcaça, por ter como referência pontos ósseos. 
OSÓRIO, J.C.S. et al. Avaliação da carcaça de caprinos e ovinos. PUBVET, Londrina, V. 6, N. 23, Ed. 209, Art. 1403, 2012.

Comprimento interno da carcaça ou medida $L$ é a distância entre a borda anterior da sínfise ísquio-pubiana e o bordo anterior da primeira costela em seu ponto médio; esta medida é tomada com fita métrica (Palsson, 1939).

Comprimento externo da carcaça é a distância entre o nascimento da cola e a base do pescoço, tomado com fita métrica (Pálsson, 1939).

O comprimento da carcaça, pelo método neozelandês, é a distância entre o bordo lateral da articulação tarso-metatarsiana à extremidade cranial do esterno, na carcaça suspensa.

\section{COMPRIMENTO DA PERNA OU MEDIDA F (Mac Meekan, 1939)}

O comprimento da perna ou a medida $F$, tomado na meia carcaça, após dividi-la longitudinalmente, é a distância mais curta entre a borda anterior da sínfise ísquio-pubiana e a porção média dos ossos do tarso (Figura 1, imagem 1). O comprimento da perna ou medida $F$, quando tomado na carcaça sem dividi-la longitudinalmente, é a distância mais curta entre o períneo e o bordo anterior da superfície articular tarso-metatarsiana. A medida pode ser tomada com fita métrica, trena ou com compasso de madeira.

PROFUNDIDADE DO PEITO OU MEDIDA Th (Pálsson, 1939)

A profundidade do peito ou medida Th é a distância máxima entre o dorso e o osso esterno, ou seja, entre a região das cruzes e a crista esternal em sua distância máxima (Figura 1, imagem 2). Tomada com fita métrica metálica (trena) ou com compasso de madeira.

\section{LARGURA DA PERNA}

A largura da perna é a distância entre as bordas interna e externa da parte superior da perna, em sua parte mais larga (Figura 1, imagem 3). Esta medida é realizada com compasso de madeira com pontas metálicas e a sua distância aferida em régua graduada em centímetros. Não é possível a tomada desta medida com fita métrica ou trena. 
OSÓRIO, J.C.S. et al. Avaliação da carcaça de caprinos e ovinos. PUBVET, Londrina, V. 6, N. 23, Ed. 209, Art. 1403, 2012.

\section{PROFUNDIDADE DA PERNA}

A profundidade da perna é a maior distância entre a borda proximal e distal da perna (Figura 1, imagem 4). Esta medida é tomada com compasso de madeira com pontas metálicas e a distância é aferida em centímetros.

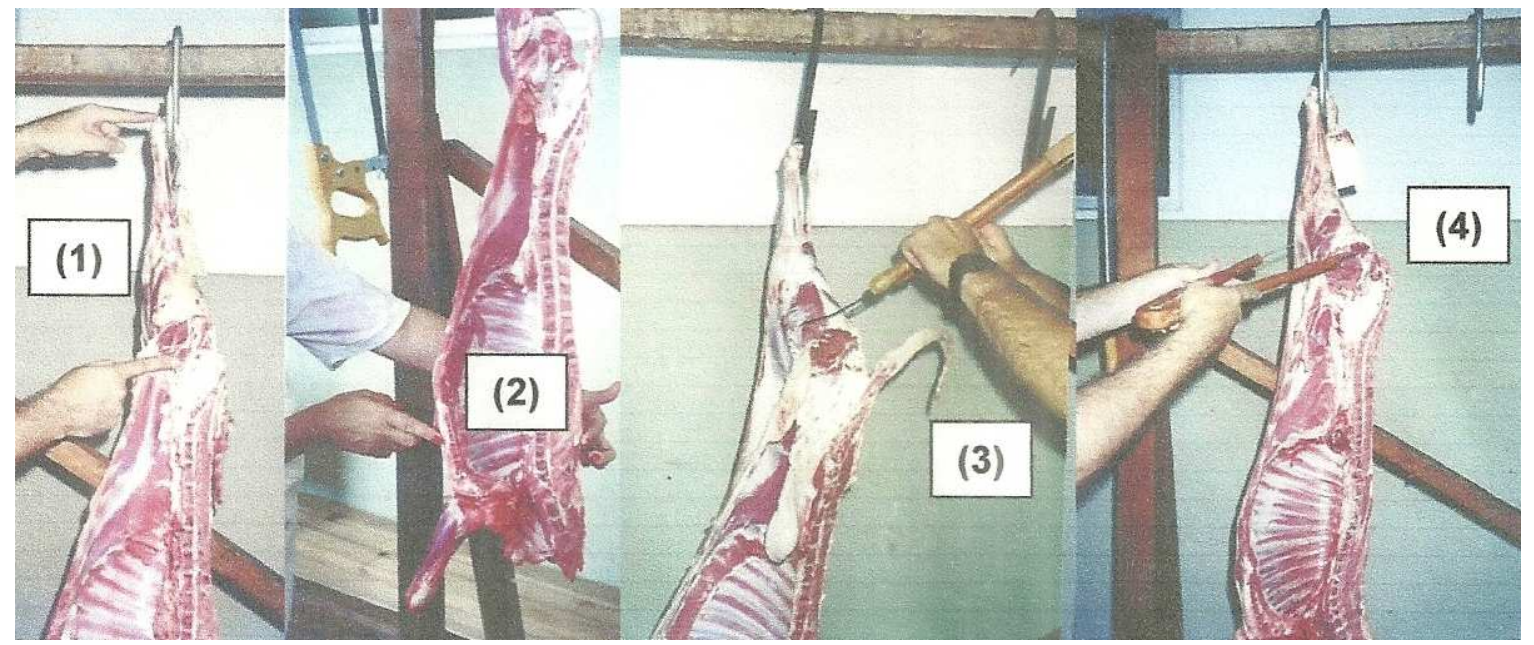

Figura1. Comprimento da perna (imagem 1), Profundidade do peito (imagem 2), Largura da perna (imagem 3) e Profundidade da perna (imagem 4).

LARGURA DA GARUPA OU MEDIDA G (Pálsson, 1939)

Largura máxima entre os trocanteres de ambos fêmur (Figura 2). Tomada com compasso ou com pelviômetro. Seu valor é influído pela distância deixada entre os membros posteriores. 
OSÓRIO, J.C.S. et al. Avaliação da carcaça de caprinos e ovinos. PUBVET, Londrina, V. 6, N. 23, Ed. 209, Art. 1403, 2012.

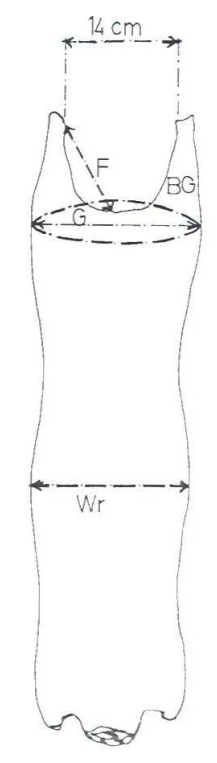

Figura 2. Medida G ou Largura da garupa, Medida BG ou Perímetro da garupa e Medida Wr ou Largura do tórax.

PERÍMETRO DA GARUPA OU MEDIDA BG (Robirson et al., 1956)

É o perímetro dessa região anatômica, tomando como referência os trocanteres de ambos fêmur (Figura 2). Tomado com fita métrica. Está correlacionada com o peso de músculo e é bom preditor da proporção de gordura da carcaça.

LARGURA DO TÓRAX OU MEDIDA Wr (Barton et al., 1944)

Largura máxima da carcaça ao nível das costelas (Figura 2). Tomada com compasso.

MEDIDAS NO MúSCULO Longissimus dorsi (lombo)

Depois do resfriamento, após separar a carcaça em duas metades (seção longitudinal), realiza-se, um corte transversal entre a $12^{a}$ e $13^{a}$ costelas (Figura 3), materializando-se a secção transversal do músculo Longissimus dorsi (dorsal largo ou $\mathrm{m}$. longissimus thoracis et lumborum). Com papel vegetal (acetato) sobre o músculo, traça-se seu contorno e, posteriormente, são tomadas as medidas de largura, profundidade e área do músculo. 

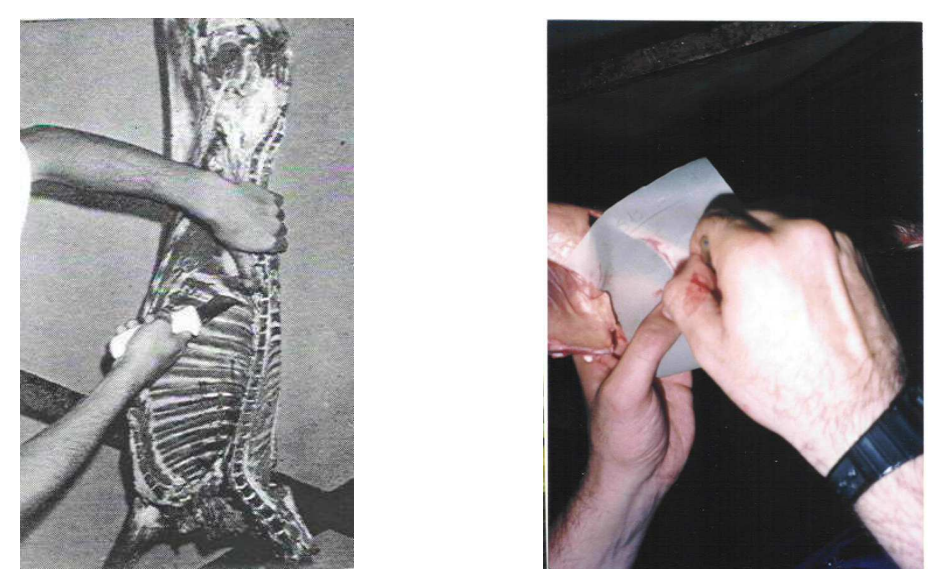

Figura 3. Materialização transversal do músculo Longissimus dorsi. 1. Enfiar a faca entre a $12^{a}$ e $13^{a}$ costelas, cortando com a faca o músculo. 2. Serrar a coluna vertebral (não seccionar o músculo com a serra, pois deforma a estrutura e superfície deste). 3. Exposição do músculo. 4. Traçar o contorno da área do músculo.

Medida A ou largura do músculo Longissimus dorsi (figura 4), é a distância máxima no corte transversal do músculo Longissimus dorsi, no sentido centro-lateral da coluna vertebral; é tomado sobre o papel vegetal.

Medida B ou profundidade do músculo Longissimus dorsi (Figura 4) é a distância máxima da profundidade do músculo no sentido dorso-ventral do animal, perpendicular a medida $A$, corresponde a porção média do terço final do referido músculo. Esta medida é tomada sobre o papel vegetal em que foi traçado o contorno do músculo.

Área do músculo Longissimus dorsi ou área de olho de lombo (Figura 4) é a área do músculo, determinada no papel vegetal em que foi tomado o traçado do músculo. A determinação da área do músculo pode ser através de: - planímetro sobre o desenho no papel vegetal.

- plástico quadriculado com um ponto no centro de cada quadrado, onde cada quadrado vale $1 / 10$ de polegada quadrada. Contando-se o número de pontos que estão incluídos pela área do músculo e dividindo-se o total por 10, obtêm- 
OSÓRIO, J.C.S. et al. Avaliação da carcaça de caprinos e ovinos. PUBVET, Londrina, V. 6, N. 23, Ed. 209, Art. 1403, 2012.

se a área do músculo. Exemplo: contando-se 102 pontos, terão 10,2 polegadas quadradas, pol. ${ }^{2}$ ou $65,80 \mathrm{~cm}^{2}$ (Müller, 1980).

- formula (medida $A / 2 \times$ medida $B / 2$ ) $\times \pi$, onde a "medida $A$ " é largura do músculo $L$. dorsi; a "medida B" é a profundidade do $L$. dorsi e " $\pi$ " é 3,1416.

- utilização de análise de imagem, através de ultrassom (Cañeque e Sañudo, 2000); que pode ser realizada no animal vivo (Delfa, 1992; Tarouco, 2003).

Sobre o músculo Longissimus dorsi, seccionado entre a $12^{\mathrm{a}}$ e $13^{\mathrm{a}}$ costelas, é tomada a Textura, Marmoreio e a Cor, visualmente e, o pH no momento do abate e 24 e 48 horas após o abate.

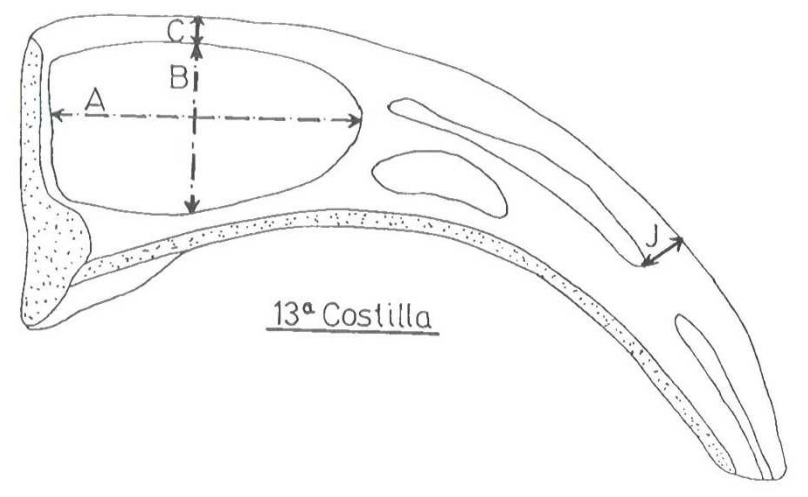

Figura 4. Medida A ou Largura do músculo Longissimus dorsi. Medida B ou profundidade do músculo Longissimus dorsi. Medida C ou Espessura da gordura de cobertura ou Espessura da gordura subcutânea. Medida J ou espessura da gordura sobre a costela.

\section{TEXTURA}

A textura do músculo Longissimus dorsi avaliada visualmente na carcaça, na secção entre a $12^{a}$ e $13^{a}$ costelas, atribui índice (Tabela 3 ) em função do tamanho dos feixes de fibras que se encontram longitudinalmente dividindo o músculo por septos perimísicos do tecido conjuntivo, ou seja, a granulação que apresenta a superfície do músculo é indicativa da quantidade de tecido conectivo (perimísio) presente no músculo. Esta avaliação visual é bem distinta da que é realizada na carne (Beltrán e Roncalés, 2000). 
OSÓRIO, J.C.S. et al. Avaliação da carcaça de caprinos e ovinos. PUBVET, Londrina, V. 6, N. 23, Ed. 209, Art. 1403, 2012.

\section{MARMOREIO}

O marmoreio, avaliado visualmente, é a apreciação da quantidade de gordura intramuscular, atribuindo-se índice de 1 a 5, com escala de 0,5 (Tabela 3). O índice de marmoreio ótimo é aquele preferido pelo mercado consumidor ou para elaboração de determinado produto.

\section{COR DA CARNE}

A avaliação visual da cor da carne na carcaça é realizada no músculo Longissimus dorsi, na secç̧ão deste entre a $12^{a}$ e $13^{a}$ costelas e, também, no músculo Rectus abdominales (representativo de músculo esquelético com conteúdo médio de hemoglobina). Nesta avaliação, é atribuído índice de 1 a 5 , com escala de 0,5 (Tabela 3 ).

Tabela 3. Escala utilizada para textura, marmoreio e cor avaliadas na carcaça.

\begin{tabular}{|c|c|c|c|}
\hline ÍNDICE & TEXTURA & MARMOREIO & COR \\
\hline 1,0 & MUITO GROSSEIRA & INEXISTENTE & ROSA CLARO \\
\hline 1,5 & & & \\
\hline 2,0 & GROSSEIRA & POUCO & ROSA \\
\hline 2,5 & & & \\
\hline 3,0 & MÉDIA & BOM & VERMELHO CLARO \\
\hline 3,5 & & & VERMELHO \\
\hline 4,0 & FINA & MUITO & \\
\hline 4,5 & & & VERMELHO ESCURO \\
\hline 5,0 & MUITO FINA & EXCESSIVO & \\
\hline
\end{tabular}

O avaliador deve buscar sempre o mesmo local e ângulo de claridade de incidência de luminosidade.

A CIE (Commission International de I'Eclairage) define a coloração percebida como o atributo visual que se compõe da combinação de conteúdos cromáticos e acromáticos. Esta coloração não depende somente da coloração física do estímulo, mas, também, de seu tamanho, forma, estrutura e 
OSÓRIO, J.C.S. et al. Avaliação da carcaça de caprinos e ovinos. PUBVET, Londrina, V. 6, N. 23, Ed. 209, Art. 1403, 2012.

estímulos que o rodeiam, além do estado do sistema visual do observador e de sua experiência em situações de observação semelhantes ou relacionadas.

A coloração da carne é dos principais fatores que determinam o valor do produto no momento de sua comercialização, já que o consumidor a relaciona com as qualidades sensoriais.

Existem outros métodos de medir a cor do músculo e da carne (Osório et al., 1998 e Cañeque e Sañudo, 2000).

MEDIDA C OU ESPESSURA DA GORDURA SUBCUTÂNEA (Pálsson, 1939)

Esta medida (Figura 4) também conhecida como espessura da gordura de cobertura, é tomada com calibrador no prolongamento da medida B.

Sobre a carcaça inteira, a espessura da gordura subcutânea dorsal, é tomada através da realização de duas incisões perpendiculares entre si, a $4 \mathrm{~cm}$ do bordo posterior da última costela e a $4 \mathrm{~cm}$ de distância da linha média (Figura 5). A medição se realiza no ponto de interseção de ambas incisões, a ambos lados da carcaça, com calibrador manual ou eletrônico. Também pode realizar-se mediante sonda ou ecografia (Huidobro et al., 2000).

MEDIDA J OU ESPESSURA DA GORDURA SOBRE A COSTELA (Starke e Joubert, 1961)

Maior espessura da gordura subcutânea, tomada sobre o bordo ventral do músculo Serratus ventralis da $12^{\mathrm{a}}$ costela (Figura 4).

MEDIDA GR, OU ESPESSURA MÁXIMA DE GORDURA

Medida tomada na secção transversal da carcaça, entre a $12^{a}$ e $13^{a}$ costelas, é a espessura dos planos musculares e adiposos que se encontram situados entre a superfície da carcaça e o osso da costela, em um ponto que dista lateralmente $11 \mathrm{~cm}$ da coluna vertebral a nível da $12^{\mathrm{a}}$ costela (Figura 5). Determinada mediante uma régua metálica graduada. A medida GR permite predizer o grau de adiposidade das carcaças com razoável precisão. 0 
OSÓRIO, J.C.S. et al. Avaliação da carcaça de caprinos e ovinos. PUBVET, Londrina, V. 6, N. 23, Ed. 209, Art. 1403, 2012.

coeficiente de correlação entre esta medida, expressada em milímetros, com a \% de gordura química da carcaça é de 0,73 (Kirton e Johnson, 1979).

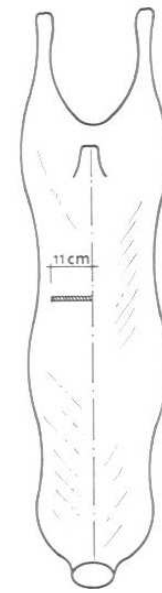

1

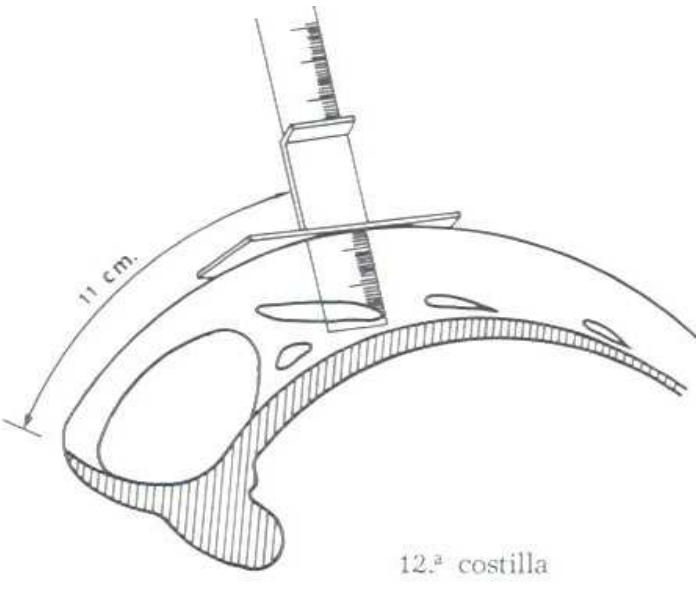

2

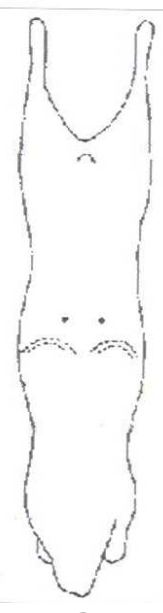

3

Figura 5. Local de determinação da Medida GR (1 e 2) e Pontos anatômicos para a realização das incisões precisas para a determinação da Espessura da gordura subcutânea dorsal (3).

COR E CONSISTÊNCIA DA GORDURA (Colomer et al., 1988)

A cor da gordura é realizada por apreciação visual da gordura subcutânea, através de escala de 1 a 3 ; sendo $1=$ branca, $2=$ creme e $3=$ amarela.

A consistência da gordura é determinada na gordura subcutânea, mediante palpação, atribuindo uma escala de 1=dura, 2=macia e 3=azeitosa.

COMPOSIÇÃO REGIONAL OU ANATÔMICA DA CARCAÇA (CORTES)

A separação da carcaça em peças (cortes) varia de uma região para outra e, inclusive, dentro de região, de um abatedouro para outro ou, em açougues. Isto, não ocorre somente no Brasil, na Espanha, por exemplo, apesar das tentativas de uma normativa, à nível comercial, da separação da carcaça em cortes (Sierra, 1970 e Colomer et al., 1972), nunca foi conseguido colocar em prática e, em cada açougue (carnicería) são realizadas separações, cortes, distintos em função do mercado e da época do ano (Saez e Sañudo, 
OSÓRIO, J.C.S. et al. Avaliação da carcaça de caprinos e ovinos. PUBVET, Londrina, V. 6, N. 23, Ed. 209, Art. 1403, 2012.

1978). Portanto, a seguir será mostrado o método mais simples, e básico, para comparação de resultados de pesquisas, de separação da carcaça em cortes.

Simultaneamente as medidas realizadas na metade esquerda da carcaça, a metade direita é pesada e separada regionalmente (cortes).

Entretanto, para melhor aproveitamento comercial e maior uniformização da qualidade da carne, de acordo com o mercado, podem ser utilizadas outras separações regionais da carcaça. Como os existentes na Espanha, descritos por Colomer et al. (1972), posteriormente normalizados, Colomer et al. (1988), Figura 6, e que foi proposto por Vergara e Gallego (2000), para que fosse utilizado para padronizar a metodologia espanhola. Sob o ponto de vista comercial esses cortes são classificados em: $1^{\text {a }}$ Categoria $\rightarrow$ pierna, costillar e badal; 2a Categoria $\rightarrow$ espalda (paletilla) e $3^{\text {a }}$ Categoria $\rightarrow$ bajos (falda ou pecho) e cuello.

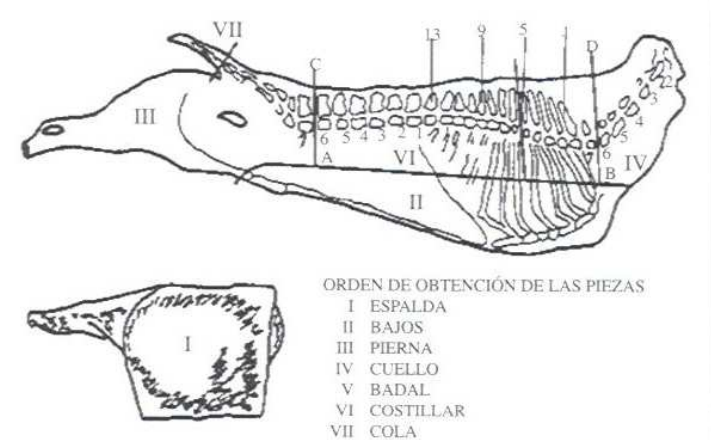

Figura 6. Composição regional ou anatômica da carcaça.

Igualmente, para a Espanha, Sañudo e Sierra (1986), apresentam uma separação da carcaça mais detalhada (dividindo o costillar em costillas de lomo e costilhas de palo e dividem a pierna em pierna e entrada) e consideram de acordo com o valor comercial de cada corte a seguinte divisão: $1^{\text {a }}$ Categoria $\rightarrow$ pierna com entrada, costillas de palo e costillas de lomo; 2a Categoria $\rightarrow$ espalda e costillas de badal e $3^{a}$ Categoria $\rightarrow$ cuello, bajos e rabo.

Ainda para a Espanha, Sánchez e Sánchez (1988), citados por Cañeque et al. (1989), descrevem uma divisão da carcaça muito similar a de Sañudo e 
OSÓRIO, J.C.S. et al. Avaliação da carcaça de caprinos e ovinos. PUBVET, Londrina, V. 6, N. 23, Ed. 209, Art. 1403, 2012.

Sierra (1986) e, Cañeque et al. (1989), apresentam uma representação gráfica de diversos cortes da carcaça de cordeiro, vendidos no mercado espanhol.

A separação regional das carcaças ovinas, no mercado da região de Paris, categoria comercial dos cortes e porcentagem, é apresentada na Figura 7 (Boccard e Dumont, 1955).

\begin{tabular}{|l|l|c|c|c|}
\hline Morceau & Cortes & Cat & $\%$ & Localização dos cortes \\
\hline 1.Gigot & Perna & I & 25,75 \\
\hline 2.Selle & Entrada de perna & I & 8,50 \\
\hline 3.Filet & $\begin{array}{l}\text { Costillas de } \\
\text { riñonada }\end{array}$ & I & 10,75 \\
\hline 4.Epaule & Paleta & II & 18,25 \\
\hline 5.Collier & Pescoço & III & 7,00 \\
\hline $\begin{array}{l}\text { 6.Carré } \\
\text { couvert }\end{array}$ & Costillas de palo & I & 11,50 \\
\hline 7.decouvert & Costillas de badal & II & 6,25 \\
\hline 8.Poitrini & Pecho & III & 12,00 \\
\hline
\end{tabular}

Figura 7. Cortes da carcaça e categoria comercial (Cat), na França.

No Brasil, há variação regional da separação anatômica da carcaça em cortes e, dentro de região, conforme a utilização, destino ou preparo da carne ovina, utiliza-se os mais variados cortes; inclusive com separação detalhada.

Determinados cortes propiciam melhor aproveitamento para carcaças leves e outros para carcaças pesadas; isso contribui para a melhora da uniformidade do produto, quanto à qualidade.

\section{COMPOSIÇÃO TECIDUAL DA CARCAÇA E DOS CORTES}

Os três tecidos fundamentais que compõe a carcaça (músculo, osso e gordura) são os determinantes do valor atribuído à carcaça e aos cortes 
OSÓRIO, J.C.S. et al. Avaliação da carcaça de caprinos e ovinos. PUBVET, Londrina, V. 6, N. 23, Ed. 209, Art. 1403, 2012.

procedentes desta. Estes caracteres são conseqüência de processos biológicos determinados pelo genótipo (raça) e o sexo, e variam com o peso e com a idade na qual o animal é sacrificado. Também, podem modificar esses tecidos, fatores ambientais, nível alimentar e composição do alimento.

A dissecção de cada corte da carcaça deve ser feita a uma temperatura ambiental (se recomenda que não seja superior aos $12^{\circ} \mathrm{C}$, aproximadamente $10^{\circ} \mathrm{C}$ ) que evite o máximo as possíveis perdas de peso por evaporação, as quais não devem exceder $2 \%$ do peso inicial do corte e no caso de serem superiores deve ser somada a quantidade que represente o tecido muscular. Além disso, com objetivo de conseguir que as perdas sejam mínimas, os cortes devem estar envolvidos em um pano úmido durante o processo de dissecção (Vergara e Gallego, 2000).

A separação tecidual, com bisturi, dos cortes da carcaça, é importante na determinação da qualidade destes. O ideal seria a separação tecidual da carcaça, nos trabalhos experimentais. Porém, por motivo de custo e tempo, principalmente, esta é feita na paleta e/ou perna.

Separam-se, os cortes, em osso, músculo, gordura e outros (onde estão as aponeurosis, vasos, etc.); sempre que possível à gordura é separada em subcutânea e intermuscular. A gordura subcutânea é a capa de gordura que cobre a superfície externa dos músculos externos, ou seja, a gordura entre a superfície do músculo e da pele. A capa de gordura que cobre o músculo cutâneo, Músculo cutaneus trunci, é considerada como gordura subcutânea. A gordura intermuscular é aquela que se encontra entre os diferentes músculos que compõem o corte.

Existe a gordura renal e pélvica. A gordura renal é a que cobre os rins e é utilizada na avaliação do estado de engorduramento. O limite anatômico da separação entre a gordura renal e a pélvica é determinado pela secção do corte que separa a perna do costilhar. A gordura renal e pélvica é utilizada para estimar a quantidade de gordura da carcaça.

Os componentes teciduais são pesados e calculados a porcentagem em relação ao peso da respectiva porção regional (paleta ou pernil). 
OSÓRIO, J.C.S. et al. Avaliação da carcaça de caprinos e ovinos. PUBVET, Londrina, V. 6, N. 23, Ed. 209, Art. 1403, 2012.

Para fins de exatidão no cálculo das percentagens, pode-se fazer o somatório dos componentes (osso + músculo + gordura + outros), obtendo o peso do corte corrigido. Isto, inclusive é necessário quando se utiliza balança diferente para a pesagem do corte e dos componentes deste. Este procedimento pode ser utilizado no cálculo das percentagens dos componentes corporais e na dos cortes da carcaça; ou seja, pode ser calculado o peso vivo corrigido e peso da meia carcaça corrigido.

A gordura é o tecido da carcaça de maior importância prática, tanto por sua grande variabilidade como por sua influência nos custos de produção. A energia requerida para produzir gordura é maior do que a para outros tecidos. Além disso, a gordura inter e intramuscular afeta a qualidade da carne (textura, maciez, sabor, aroma) em função de sua quantidade e composição.

A dissecação da carcaça e de seus cortes não é prática a nível comercial, assim, as pesquisas buscam preditores e equações que possam estimar a composição tecidual. Resultados de Pálsson (1939) mostram que a medida B é indicador da musculatura da carcaça. A correlação desta medida com a quantidade de músculo por disseç̧ão é de 0,47 para cordeiros (machos castrados ou fêmeas com menos de 12 meses) e de 0,60 para borregos (entre 12 e 24 meses). A espessura de gordura de cobertura, medida C, apresenta correlação com a gordura total de cobertura da carcaça de 0,70 (cordeiros) e de 0,95 (borregos). A correlação entre o comprimento do osso da perna e o peso total do esqueleto da carcaça é de 0,75 (cordeiros) e de 0,81 (borregos). A superfície do músculo longissimus dorsi apresenta com o peso da musculatura total da carcaça uma correlação de 0,43 (Cole et al., 1960).

Nos experimentos, em função do custo da dissecção completa da carcaça ou da meia carcaça, a composição tecidual poderá ser determinada a partir da dissecção dos cortes e pela facilidade de obtenção, assim como pelos elevados coeficientes de correlação entre sua composição e a composição da carcaça é recomendada a utilização da paleta como preditora da composição total da carcaça (Sañudo, 1980; Diestre, 1985; Vergara e Gallego, 2000). Porém, as equações de predição são restritas para genótipo, sistema de produção e 
OSÓRIO, J.C.S. et al. Avaliação da carcaça de caprinos e ovinos. PUBVET, Londrina, V. 6, N. 23, Ed. 209, Art. 1403, 2012.

amplitude de peso; o que deve ser levado em consideração na hora de aplicálas (Kempster e Cuthbertson, 1977; Delfa, 1992; Vergara e Gallego, 2000).

Assim, é evidente o interesse de obter equações de predição para os diferentes genótipos em seus sistemas de criação e em amplitudes de peso, para evitar erros com as equações de predições obtidas em outras condições e genótipos (Delfa, 1992).

Delfa et al. (1991a) concluem que:

- o peso da carcaça fria é o melhor preditor da gordura intermuscular da carcaça.

- quando o peso de carcaça fria é introduzido em equações de regressão junto com a medida $C$, estima com elevada precisão o músculo e a gordura subcutânea da carcaça e, quando se introduz com a condição corporal estima com precisão a gordura pélvica e renal da carcaça; e, quando se introduz com a espessura de gordura lombar estima com elevada precisão a gordura total da carcaça, a gordura pélvica e renal e o músculo total da carcaça.

Delfa et al. (1991b) concluem que:

- o ultra-som é eficaz para determinar a espessura da gordura lombar na carcaça.

- o ponto anatômico onde se realiza a espessura da gordura no animal pode alterar a precisão da estimação da espessura da gordura na carcaça.

- o ultra-som pode ser considerado pouco eficaz para determinar a profundidade real do músculo longissimus dorsi e portanto para determinar o peso deste músculo na carcaça.

- as medidas de espessura da gordura lombar in vivo com ultra-som ou na carcaça, são as melhores preditoras do músculo e gordura total da carcaça.

Também, é feita a relação músculo:gordura, músculo:osso e gordura:osso. Normalmente, com o aumento de peso de carcaça há diminuição da relação músculo:gordura e aumento do índice músculo:osso; isso porquê, a musculatura cresce em velocidade menor que a gordura e maior que o osso. Porém, dentro das amplitudes de pesos comerciais as variações nos índices M:O apresentam menor importância que a de M:G. 
OSÓRIO, J.C.S. et al. Avaliação da carcaça de caprinos e ovinos. PUBVET, Londrina, V. 6, N. 23, Ed. 209, Art. 1403, 2012.

\section{MUSCULOSIDADE}

A musculosidade da carcaça é a espessura do músculo em relação às dimensões do esqueleto. Segundo Purchas et al. (1991), uma medida objetiva de musculosidade é a relação entre a profundidade média de um grupo de músculos ao redor de um osso e o comprimento deste osso. A profundidade média dos músculos é, indiretamente, avaliada como a raiz quadrada do peso de um grupo de músculos, dividida pelo comprimento de um osso adjacente. Esses autores avaliam a musculosidade da perna pela dissecção dos principais músculos ao redor do fêmur e concluem que diferenças na musculosidade nem sempre acompanham diferenças na relação músculo:osso.

Entretanto, medidas objetivas da musculosidade são pouco relatadas, devido às dificuldades em se medir a profundidade média do músculo. A maioria dos trabalhos utilizam escores subjetivos (Kempster et al., 1981; Kirton et al., 1983).

Musculosidade $=$ (raiz quadrada ( (comprimento do fêmur)) / comprimento do fêmur). Purchas et al. (1991). Cinco músculos da perna: Biceps femoris, Semimembranosus, Semitendinosus, Quadriceps femoris e Adductor.

$\mathrm{pH}$

$\mathrm{O}$ pH é o logaritmo negativo da concentração de prótons de uma dissolução. Seu valor é expressado em de zero (ácido) a 14 (básico). A medida potenciométrica do $\mathrm{pH}$ se baseia no registro da diferença de potencial elétrico entre um eletrodo de medição e outro de referência (Garrido e Bañon, 2000).

$\mathrm{O}$ pH da carcaça, no músculo longissimus dorsi, é importante no processo de transformação do músculo em carne. Influi nas características organolépticas da carne não somente o $\mathrm{pH}$ final, como também a velocidade de queda do $\mathrm{pH}$ do abate até as primeira 48 horas, principalmente.

Após o abate, antes de pesar a carcaça, é tomado o $\mathrm{pH}$, realizando-se uma secção no músculo Longissimus dorsi, na região lombar (Figura 8). Devese esperar a fixação do valor do phmetro, ou seja, quando parar a oscilação, o que ocorre em aproximadamente um minuto. 


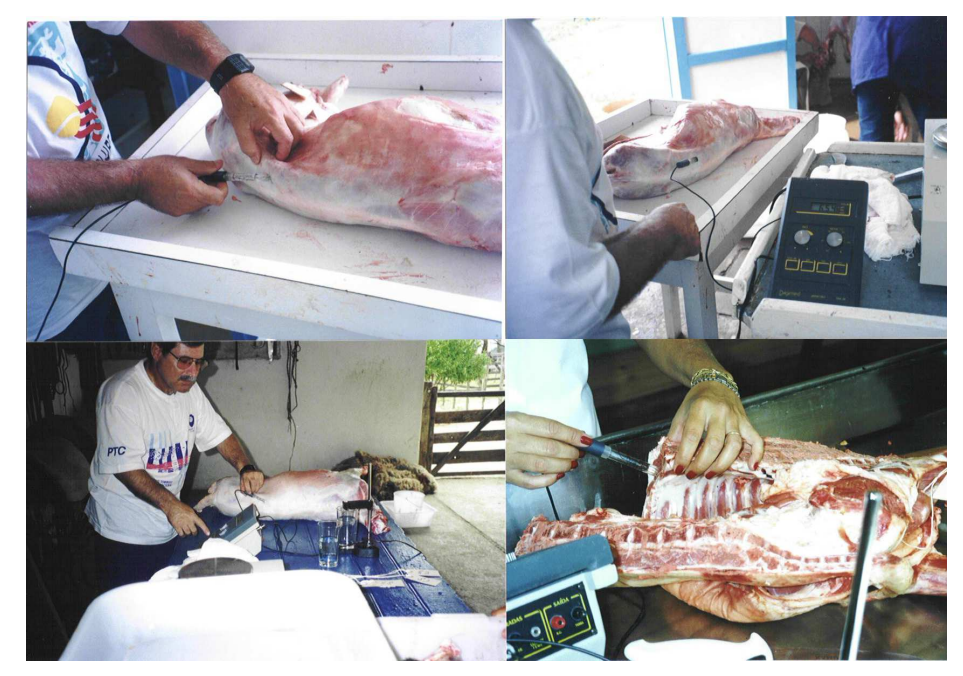

Figura 8. Tomada do $\mathrm{pH}$, no momento do abate e 24 horas após, quando é realizado na meia carcaça.

\section{COMPACIDADE DA CARCAÇA E DA PERNA}

A compacidade da carcaça é a relação entre o peso e o comprimento da carcaça $(P C F / L)$ e a compacidade da perna é a relação entre a largura da garupa e o comprimento da perna (G/F).

\section{CONCLUSÕES}

Há necessidade de uma avaliação da carcaça e que esta forneça uma imagem inequívoca.

A utilização das características descritivas da carcaça depende da finalidade e a eleição de uma ou outras deve levar em consideração o aspecto econômico, a facilidade e a precisão de medir ou estimar as características.

Existe necessidade de uma descrição detalhada das características da carcaça e de equações de predição, principalmente, da composição tecidual desta, para os genótipos, sistemas de produção (em especial alimentação) e sexo dos ovinos, no Brasil.

Deve-se relacionar (coeficientes de correlação e equações de predição) a carcaça com características no animal (vivo) e na carne.

A composição dos tecidos da carcaça é o critério mais exato para atender o consumidor e pode ser modificado pelo produtor. 
OSÓRIO, J.C.S. et al. Avaliação da carcaça de caprinos e ovinos. PUBVET, Londrina, V. 6, N. 23, Ed. 209, Art. 1403, 2012.

Na carcaça em nível de linha de abate comercial pela necessidade de rapidez, o peso, estado de engorduramento e conformação visual são características que devem ser utilizadas; e, o ultrassom em tempo real, pelo baixo custo, atualmente, em relação aos outros métodos de estimação da composição dos tecidos da carcaça, em muito ajudaria para uma avaliação mais exata da qualidade da carcaça.

$\mathrm{O}$ pH e compacidade da carcaça, também são características importantes a considerar, tanto a nível de distribuidoras de carne como em experimentos.

Nos experimentos, a composição tecidual da carcaça é da máxima importância.

A separação anatômica da carcaça representa contribuição importante no incremento da qualidade da carne, tanto pelo melhor aproveitamento, como pela uniformização da qualidade.

\section{BIBLIOGRAFIA}

Barton, R.A.; Phillips, T.O.; Clark, E.A. Influence of Sex on fat lamb quality. Ann. Conf. Of N.Z. Society of Animal Production. Prod. Proc., XI, 1944.

Beltrán, J.A.; Roncalés, P. Determinación de la textura. In: Cañeque e Sañudo, 2000. Metodología para el estudio de la calidad de la canal y de la carne en rumiantes. Ministerio de Ciencia y Tecnologia. Monografías INIA: Ganadera, n.1, p.167-172, 2000.

Boccard, R.; Dumont, B.L. Etude de la producción de la viande chez les ovins. I. La coupe des carcasses. Définition d'une découp de référence. Annales de Zootechnia, v.3, p.241-257, 1955.

Cañeque, V.; Huidobro, F.R.; Dolz, J.F. et al. Producción de carne de cordero. Ministerio de Agricultura, Pesca y Alimentación. Colección Técnica. 520 páginas, 1989.

Cañeque, V.; Sañudo, C. Metodología para el estudio de la calidad de la canal y de la carne en rumiantes. Ministerio de Ciencia y Tecnología. Instituto Nacional de Investigación y Tecnología Agraria y Alimentaria (INIA). Monografías INIA: Ganadera, n.1, 255 p., 2000.

Cañeque, V.; Sañudo, C. Estandarización de las metodologías para evaluar la calidad del producto (animal vivo, canal, carne y grasa) en los Rumiantes. Madri. Monografias INIA: Ganadera, n.3, 448p., 2005.

Cole, J.W.; Orme, L.E.; Kincaid, C.M. Relationship of loin eye area separable lean of various beef cut carcass measurements to total carcass lean in beef. J. of Anim. Sci., v.19, p.89-100, 1960. 
Colomer, F.; Dumont, B.L.; Murillo, N.L. Descripción del despiece ovino Aragonés y definición de un despiece de referencia normalizado. Anales del Instituto Nacional de Investigación Agraria, Serie: Producción Animal, n.3, p.79-108, 1972.

Colomer, F. La classificación de las canales ovinas y bovinas. Ministerio de Agricultura. INIA. Serie: Producción Animal, n.5, 320p., 1979.

Colomer, F. Producción de canales ovinas frente al mercado común europeo. Interés de la denominación de origen del ternasco aragonés. Diputación Provincial. Institución Fernando el Católico. Publicación número 1052. Zaragoza, España. 111p., 1986.

Colomer, F.; Morand-Fehr, P.; Kirton, A. et al. Métodos normalizados para el estudio de los caracteres cuantitativos y cualitativos de las canales caprinas y ovinas. Ministerio de Agricultura, Pesca y Alimentação. Cuadernos INIA, n.17, 41p., 1988.

De Boer, H.; Dumont, B.L.; Pomeroy, R.W. et al. Manual on E.A.A.P. reference methods for the assessment of carcass characteristics in cattle. Livestock Prod. Sci., v.1, p.151-164, 1974.

Delfa, R.; Teixeira, A.; Colomer, F. Cold carcass weight, fat thickness, C measurement and longissimus dorsi depht for predicting the carcass composition of Rasa Aragonesa ewes with different body condition scores. Options Méditerranéennes, v.14, p.31-36, 1991a.

Delfa, R.; Teixeira, A.; Blasco, I. et al. Ultrasonic estimates of fat thickness, C measurement and longissimus dorsi depth in Rasa Aragonesa ewes with same body condition score. Options Méditerranéennes, v.14, p.37-42, 1991b.

Delfa, R. Clasificación de canales ovinas en la CEE. El quinto cuarto. Zaragoza. Diputación General de Aragón. Departamento de Agricultura, Ganaderia y Montes. 117p., 1992.

Diestre, A. Estudio de los factores biologicos determinantes del desarrollo de las canales de cordero y de sus caracteristicas comerciales. Tesis Doctoral. Facultad de Veterinária. Universidad de Zaragoza. España. 224p., 1985.

Dumont, B.L. Principe de description des carcasses ovines. Pâtre, n.183, p.23-25, 1971.

Esteves, R.M.G.; Osório, J.C.S.; Osório, M.T.M. et al. Avaliação in vivo e da carcaça e fatores determinantes para o entendimento da cadeia da carne ovina. Revista Brasileira de Agrociência, v.16, n.1-4, p.101-108, 2010.

Garrido, Ma.D.; Bañon, S. Medida del pH. In: Cañeque e Sañudo, 2000. Metodología para el estudio de la calidad de la canal y de la carne en rumiantes. Ministerio de Ciencia y Tecnologia. Monografías INIA: Ganadera No 1.p.145-155. 2000.

Huidobro, F.R.; Cañeque, V.; Onega, E. et al. Morfología de la canal ovina. In: Cañeque e Sañudo, 2000. Metodología para el estudio de la calidad de la canal y de la carne en rumiantes. Ministerio de Ciencia y Tecnologia. Monografías INIA: Ganadera n.1, p.81-102, 2000.

Kempster, A.J.; Croston, D.; Jones, D.W. Value of conformation as na indicator of sheep carcass composition within and between breeds. Animal Production, v.33, p.39-49, 1981.

Kirton, A.H.; Johnson, D.L. Interrelationships between GR and other lamb carcass fatness measurements. Proc. N. Z. Soc. Anim. Prod., v.39, p.194-201, 1979.

Kirton, A.H.; Wood, E.G.; Duganzinch, D.M. Comparison of well and poorly muscled lamb carcasses as selected by experienced meat industry personnel. Proc. of the $\mathbf{N}$. Zealand Society of Animal Science, v.43, p.111-113, 1983.

McMeekan, C.P. The Cambridge block test for fat lamb. Ann. Meat of Sheep Farmers, Proc. VIII. p.52-57, 1939. 
Müller, L. Normas para avaliação de carcaças e concurso de carcaças de novilhos. UFSM, Departamento de Zootecnia. Sta Maria, 31p., 1980.

Müller, L. Normas para avaliação de carcaças e concurso de carcaças de novilhos. Universidade Federal de Santa Maria. Sta Maria, RS, 1987, 31 pág.

Osório, J.C.; Osório, M.T.; Jardim, P. et al. Métodos para avaliação da produção de carne ovina: in vivo, na carcaça e na carne. Ed. Universitária - UFPEL. Pelotas, 107p., 1998.

Osório, J.C.; Osório, M.T.; Oliveira, N. et al. Qualidade, morfologia e avaliação de carcaças. Ed. Universitária - UFPEL. Pelotas. 195p., 2002.

Osório, J.C.S.; Osório, M.T.M. Produção de carne ovina: Técnicas de avaliação "in vivo" e na carcaça. Programa de Pós-Graduação em Zootecnia. Universidade Federal de Pelotas. $73 p ., 2003$.

Osório, J.C.S.; Osório, M.T.M.; Esteves, R.M. et al. Relación entre la evaluación in vivo e de la canal y entre evaluadores em corderos. In: Jornadas sobre Producción Animal, 11, 2005, Zaragoza. Anais... Zaragoza: Asociación Interprofesional para el Desarrollo Agrário, v.2, p.670-672, 2005.

Osório, J.C.S.; Osório, M.T.M.; Esteves, R.M.G. et al. Avaliação in vivo e da carcaça e efeitos de lote e sexo. In: Reunião Anual da Sociedade Brasileira de Zootecnia, 43, 2006, João Pessoa. Anais... João Pessoa: Sociedade Brasileira de Zootecnia, v.1, p.1-4. CDROM, 2006.

Palsson, H. Meat qualities in the sheep with special reference to Scottish breeds and crosses. I. Carcass measurements and "sample joints" as indices of quality and composition. J. of Agricultural Science, v.29, p.544-626, 1939.

Purchas, R.; Davies, A.; Abdullah, A. Na objective measure of muscularity: changes with animal growth and differences between genetic lines of Southdown sheep. Meat Science, v.30, p.81-94, 1991.

Robinson, J.J.; Binett, E.E.; Doig, A.G. Fat lamb studies in Victoria. I. Na assessment of the relative value of various external measurements for differenciating beetween various grades of export lamb carcasses. Australian Journal of Agricultural Research, n.7, p.345-365, 1956.

Saez, E.; Sañudo, C. Variaciones de los escandallos de ternasco. Incidencias en los resultados económicos. IEPGE, Universidad de Zaragoza. n.45, 17p., 1978.

Sañudo, C. Calidad de la canal y de la carne en el ternasco aragonés. Tesis Doctoral. Facultad de Veterinaria. Universidad de Zaragoza. 337p., 1980.

Sañudo, C.; Sierra, I. Calidad de la canal en la especie ovina. OVINO, One S.A., Barcelona, España. Septiembre. p.127-153, 1986.

Sierra, I. La conformación en el ganado ovino: Su influencia en el rendimiento canal y en el despiece. IEPGE, Universidad de Zaragoza, Zaragoza, España. n.5, 14p., 1970.

Sierra, I. El ternasco aragones: descripción y caracteristicas fundamentales. Instituto de Economia y Producciones Ganaderas del Ebro, Univ. de Zaragoza. n.19, 65p., 1974.

Starke, J.S.; Joubert, D.M. A score card for lamb and mutton carcasses. J. of Agri. Sci., v.57, p.319-323, 1961.

Tarouco, J.U. Métodos de avaliação corporal in vivo para estimar o mérito da carcaça ovina. $2^{\circ}$ SINCORTE, João Pessoa, p.443-449, 2003.

Vergara, H.; Gallego, L. Composición de la canal ovina. In: Cañeque e Sañudo. Metodología para el estudio de la calidad de la canal y de la carne en rumiantes. Ministerio de Ciencia y Tecnologia. Monografías INIA: Ganadera, n.1, p.125-136, 2000. 